(2) Open Access Full Text Article

\title{
Downregulation of A20 increases the cytotoxicity of IFN- $\gamma$ in hepatocellular carcinoma cells
}

\author{
This article was published in the following Dove Press journal: \\ Drug Design, Development and Therapy \\ 26 September 2017 \\ Number of times this article has been viewed
}

\section{Lei Yin* \\ Zheng Fang* \\ Ning-jia Shen \\ Ying-he Qiu \\ Ai-jun Li \\ Yong-jie Zhang}

The Second Department of Biliary Surgery, Eastern Hepatobiliary Surgery Hospital, Second Military Medical University, Shanghai, China

*These authors contributed equally to this work
Correspondence: Yong-jie Zhang The Second Department of Biliary Surgery, Eastern Hepatobiliary Surgery Hospital, Second Military Medical University, No. 225 Changhai Road, Yangpu District, Shanghai 200438, China Email zhangyongjiesh@yahoo.com

\begin{abstract}
Hepatocellular carcinoma (HCC) is a highly fatal disease mandating development of novel, effective therapeutic strategy. Interferon-gamma (IFN- $\gamma$ ) is a pleiotropic cytokine with immunomodulatory, antiviral, and antitumor effects. Although IFN- $\gamma$ is a promising antitumor agent, its application is limited by resistance in tumor cells. A20 is a zinc-finger protein that was initially identified as a gene product induced by tumor necrosis factor $\alpha$ in human umbilical vein endothelial cells. In this study, we found that silencing of A20 combined with IFN- $\gamma$ significantly represses cell viability, and induces apoptosis and cell-cycle arrest in HCC cells. By investigating mechanisms implicated in A20 and IFN- $\gamma$-mediated signaling pathways, we revealed that the phosphoinositide 3-kinase/Akt signaling pathway and antiapoptotic B-cell lymphoma 2 proteins were repressed. Moreover, we also found that phosphorylation of STAT1 and STAT3 was significantly enhanced after the downregulation of A20 in combination with treatment of IFN- $\gamma$. Inhibitor of STAT1 but not STAT3 could block the antitumor effect of IFN- $\gamma$. Therefore, targeting A20 enhances the cytotoxicity of IFN- $\gamma$ against HCC cells and may present a promising therapeutic strategy for HCC.
\end{abstract}

Keywords: IFN- $\gamma$, A20, hepatocellular carcinoma, PI3K/Akt, STAT1, STAT3

\section{Introduction}

Hepatocellular carcinoma (HCC), a severe global health problem, is one of the most common carcinomas throughout the world. ${ }^{1}$ Although improvements in diagnostic methods have improved the early diagnosis of HCC, the median survival of HCC patients is still low. Today, the main strategy used to treat HCC includes surgery and chemotherapy. ${ }^{2}$ However, recurrence and metastasis after surgery, as well as resistance to chemotherapy remain as a major obstacle. Therefore, novel interventions are urgently needed for HCC.

Interferon-gamma (IFN- $\gamma$ ), which can be secreted by Th1 and natural killer cells, is a homodimeric glycoprotein with multiple biological functions such as antiviral and immunomodulatory ones. ${ }^{3}$ In addition, IFN- $\gamma$ can exert antitumor activity via inducing cell-cycle arrest and/or apoptosis in various carcinoma cells such as glioma cells, multiple myeloma cells, gastric cancer cells and cervical cancer cells. ${ }^{4-7}$ Although IFN- $\gamma$ has potential value, the application of IFN- $\gamma$ in the treatment of solid tumors has been limited. ${ }^{8}$ For instances, some tumors requiring high doses of IFN- $\gamma$ for a therapeutic effect would cause undesired side effects. ${ }^{8,9}$ Therefore, it is essential to look for a strategy to enhance the therapeutic effect of IFN- $\gamma$ or decrease the dosage without affecting the effect.

A20, also known as tumor necrosis factor $\alpha$ (TNF- $\alpha)$-induced protein 3 , is a zincfinger protein that can be induced by TNF- $\alpha .{ }^{10}$ Many studies have shown that A20 
regulates inflammation signaling pathways and functions as an ubiquitin-editing enzyme to repress nuclear factor- $\kappa \mathrm{B}$ signaling pathway, thereby acting as a vital anti-inflammatory factor. ${ }^{11}$ In addition, the expression of A20 has been found dysregulated in various carcinomas, and mounting evidence suggests that A20 participates in the development of cancer. ${ }^{12,13}$ The role of A20 in HCC is still controversial. For example, A20 was found to suppress the proliferation, invasion and metastasis of HCC cells. ${ }^{12}$ On the other hand, A20 protects HCC cells from apoptosis induced by TRAIL, which is a potent antitumor ligand that belongs to the TNF family. ${ }^{13}$ However, the impact of A20 on the antitumor activity of IFN- $\gamma$ in HCC had never been investigated.

In the present study, a series of experiments were designed to explore the effects of silencing of A20 on cytotoxicity of IFN- $\gamma$ in HCC cells. We found that silencing of A20 enhances the cytotoxicity of IFN- $\gamma$ against HCC cells. The possible mechanism of A20 affecting the cytotoxicity of IFN- $\gamma$ was also investigated. Downregulation of A20 leads to the repression of phosphoinositide 3-kinase (PI3K)/Akt signaling pathway and antiapoptotic B-cell lymphoma 2 (Bcl-2) proteins. Moreover, phosphorylation of STAT1 and STAT3 was enhanced after the downregulation of A20 in combination with IFN- $\gamma$.

\section{Materials and methods}

\section{Cell culture and chemicals}

Human HCC cell lines HepG2 and Huh9 were obtained from Shanghai Institutes for Biological Sciences (Shanghai, China). Cells were cultured in RPMI1640 medium (Thermo Fisher Scientific, Waltham, MA, USA) supplemented with $10 \%$ fetal bovine serum (Thermo Fisher Scientific). The cells were cultured in a humidified atmosphere with $5 \%$ carbon dioxide at $37^{\circ} \mathrm{C}$. IFN- $\gamma$ was purchased from Solarbio (Beijing, China). FLUD (Fludarabine) and S3I (STAT3 inhibitor) were purchased from Sigma-Aldrich Co. (St Louis, MO, USA). z-DEVD-fmk, z-LEHD-fmk, and z-IETD-fmk were purchased from Selleckchem (Houston, TX, USA). Propidium was purchased from Sigma-Aldrich Co. Annexin V apoptosis detection kit was purchased from BD Biosciences (San Jose, NJ, USA).

\section{MTT assay}

MTT (3-[4,5-dimethylthiazol-2-yl]-2,5-diphenyltetrazolium bromide) assay was used to measure cell proliferation. Briefly, cells were plated at $1 \times 10^{4} /$ well into 96 -well plates. After treatment, $10 \mu \mathrm{L}$ of $5 \mathrm{mg} / \mathrm{mL}$ MTT (Sigma-Aldrich Co.) was added to the wells, and plates were then incubated at $37^{\circ} \mathrm{C}$ for additional $4 \mathrm{~h}$. The reaction was terminated with dimethyl sulfoxide. Subsequently, absorbance at $450 \mathrm{~nm}$ was measured using a microplate reader (Beckman Coulter, Brea, CA, USA). Cell viability was calculated as follows: cell viability $\%=($ mean absorbency in treated wells $) /($ mean absorbency in control wells) $\times 100$. Each experiment was performed in triplicate.

\section{Cell-cycle analysis}

Cellular DNA content was measured by flow cytometry. Cells grown in six-well plates were collected after treatment. After being washed with ice-cold phosphate-buffered saline, the cells were fixed with $75 \%$ ethanol overnight at $4^{\circ} \mathrm{C}$. Cells were then incubated with RNase A for $30 \mathrm{~min}$ at room temperature and stained with propidium iodide (PI). Cell cycle was then measured by flow cytometry (Becton Dickinson, Franklin Lakes, NJ, USA).

\section{Apoptosis analysis}

Cellular apoptosis was measured by flow cytometry. Cells cultured in six-well plates were collected after treatment. The cell pellets were resuspended in $100 \mu \mathrm{L}$ of binding buffer and stained with Annexin $\mathrm{V}$ apoptosis detection kit (BD Biosciences) according to the manufacturer's guide. Then the samples were analyzed by flow cytometry (Becton Dickinson).

\section{Generation of stable cell clones}

The HepG2 and Huh9 cells were transduced with lentiviruses carrying shRNA against human A20 (sh-A20) or a scrambled negative control (sh-NC) using the lentiviral vector, pLenti6.3/V5-DEST (Genechem, Shanghai, China). The target sequence of sh-A20 was 5'-GAAGCTCAGAA TCAGAGATTT-3', and the sequence of sh-NC was 5'-AACAGAGGTTACACGAATCGG-3'. Stable clones were selected in a medium containing $3 \mu \mathrm{g} / \mathrm{mL}$ puromycin for 2-3 weeks.

\section{Western blot assay}

Protein concentrations of cellular lysates were measured by the bicinchoninic acid protein assay kit (Thermo Fisher Scientific) and proteins were separated on sodium dodecyl sulfate polyacrylamide gel electrophoresis gels. Separated proteins were then transferred on polyvinylidene difluoride membranes (EMD Millipore, Billerica, MA, USA). Membranes were blocked with $5 \%$ nonfat milk or BSA at room temperature for $1 \mathrm{~h}$ followed by incubation with primary antibodies against A20 (Santa Cruz Biotechnology Inc., Dallas, TX, USA), cyclin A, CDK1, CDK2, Mcl-1, Bax, Bcl-2, Bcl-x1, p-Akt, Akt, PI3K (p85), p-STAT1, STAT1, p-STAT3, 
STAT3, caspase-8, caspase-9, caspase-3, cleaved PARP (Cell Signaling Technology), p-PI3K (p85 phosphorY464) and glyceraldehyde 3-phosphate dehydrogenase (Sigma-Aldrich Co.). The membranes were then incubated with secondary antibodies. The membrane was finally washed with TBS-T and protein expression was determined with enhanced chemiluminescence (Pierce, Rockford, IL, USA).

\section{Statistical analysis}

All values were expressed as the mean \pm SD. Significant differences between groups were assessed using a one-way analysis of variance, followed by Student's $t$-test. These analyses were performed using GraphPad Prism 6 (GraphPad Software, Inc., La Jolla, CA, USA). $P<0.05$ was considered statistically significant.

\section{Results}

\section{Downregulation of A20 acts synergistically with IFN- $\gamma$ to inhibit the proliferation of human HCC cells}

To investigate whether A20 affects the antitumor effect of IFN- $\gamma$ in HCC cells, stable A20-knockdown (sh-A20) and negative control (sh-NC) cell lines were generated using HCC cell lines HepG2 and Huh7. As shown in Figure 1A, Western blot confirmed that A20 expression was significantly declined in both sh-A20 cells compared with sh-NC and wild-type (wt) cells. Then wt, sh-NC and sh-A20 cells were treated with various concentrations of IFN- $\gamma(10,20$, 50 and $100 \mathrm{ng} / \mathrm{mL}$ ) for $24 \mathrm{~h}$ or $100 \mathrm{ng} / \mathrm{mL}$ of IFN- $\gamma$ for various time intervals $(12,24,36$ and $48 \mathrm{~h})$, then cell viability was measured by the MTT assay. As shown in Figure 1B and $\mathrm{C}$, cell viability of sh-A20 was significantly reduced in a dose- and time-dependent manner compared with control cells after the treatment with IFN- $\gamma$ in both HepG2 and Huh7 cells. Because the extent of A20 downregulation by sh-A20 was higher in HepG2 than in Huh9, we chose HepG2 cells for the following studies.

\section{Downregulation of $\mathrm{A} 20$ acts synergistically with IFN- $\gamma$ to induce cell-cycle arrest at the $S / M$ phase in HepG2 cell}

We next addressed whether the decreased viability was associated with changes in the cell cycle, and a flow cytometric analysis was performed to measure the distribution of cell cycles after the treatment with IFN- $\gamma$. As shown in Figure 2A, A20 knockdown combined with IFN- $\gamma$ treatment significantly induced cell-cycle arrest in the $\mathrm{S} / \mathrm{M}$ phases and reduced the proportion of cells in G0/G1 phase compared with A2 0 knockdown or IFN- $\gamma$ treatment alone.
To better understand the underlying mechanisms, Western blot was performed to measure the levels of cell-cycle regulators. We found that cell-cycle-related proteins such as cyclin A, CDK1 and CDK2 were significantly decreased in sh-A20 cells treated with IFN- $\gamma$ compared with the others (Figure 2B).

\section{A20 silencing enhances IFN- $\gamma$-induced apoptosis via the activation of caspase-9/-3 pathway}

Then we determined whether silencing of A20 combined with IFN- $\gamma$ could affect the process of apoptosis by using an Annexin V-FITC/PI staining assay. After treatment with $100 \mathrm{ng} / \mathrm{mL}$ IFN- $\gamma$ for $24 \mathrm{~h}$, sh-A20 cells exhibited significantly higher apoptosis levels than sh-NC cells (Figure 3A). Next, we analyzed the change of levels of caspases. As indicated in Figure 3B, the protein levels of initiator caspase-9 as well as effector caspase- 3 were found to be significantly diminished after the treatment with IFN- $\gamma$ in sh-A20 but not sh-NC cells. On the other hand, the protein levels of caspase- 8 remained largely unchanged after the treatment with IFN- $\gamma$ in both cell lines (Figure 3B). To further confirm the changes in caspase levels observed via the Western blotting analysis, a caspase activity assay was performed to evaluate the activity of caspase-3, -8 and -9 . As shown in Figure $3 \mathrm{C}$, the activity of caspase- 3 and -9 was significantly increased in sh-A20 cells treated with IFN- $\gamma$. However, the caspase- 8 activity was found to exhibit no changes among different groups (Figure 3C). The role of caspases was further confirmed by the inhibitory experiment. IFN- $\gamma$-induced apoptosis and inhibition of cell viability in sh-A20 cells were significantly blocked by caspase-3 inhibitor Z-DEVD-fmk and caspase-9 inhibitor Z-LEHD-fmk but not by caspase- 8 inhibitor Z-IETD-fmk (Figure 3D). Taken together, these data indicated that sh-A20/IFN- $\gamma$ induced apoptosis via the caspase-9/-3 pathway.

\section{Downregulation of A20 combined with IFN- $\gamma$ repressed the antiapoptotic $\mathrm{Bcl}-2$ proteins and $\mathrm{PI} 3 \mathrm{~K} / \mathrm{Akt}$ pathway}

Then we explored the possible mechanisms of sh-A20/ IFN- $\gamma$-induced apoptosis. The apoptotic pathway is regulated by the Bcl-2 protein family. We evaluated the change of Bcl-2 family proteins by Western blot. As shown in Figure 4A, IFN- $\gamma$ treatment resulted in significant decrease of antiapoptotic Bcl-2 family proteins Bcl-2, Bcl-xl and Mcl-1 in sh-A20 cells. Meanwhile, the proapoptotic Bcl-2 protein Bax was upregulated in sh-A20 cells after IFN- $\gamma$ treatment. It is well documented that PI3K/Akt signaling 
A

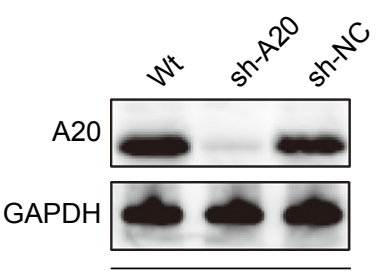

HepG2

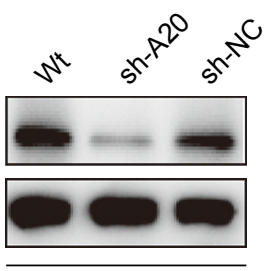

Huh7
HepG2

B

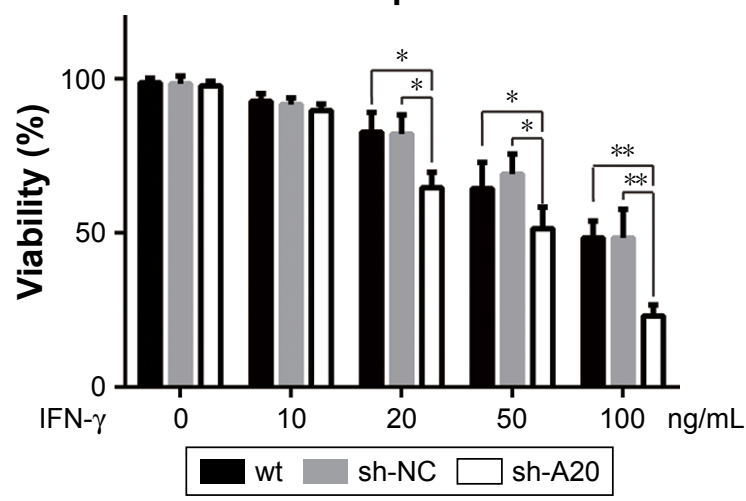

Huh7

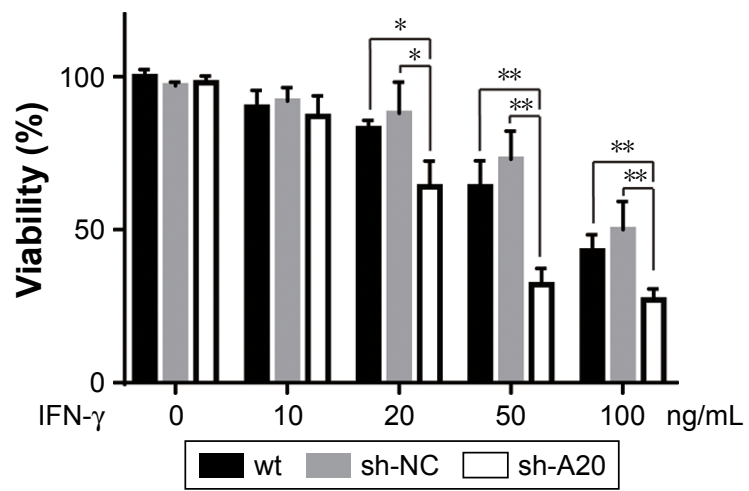

HepG2

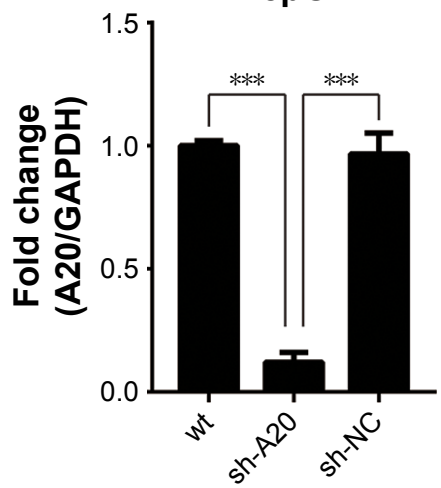

Huh7

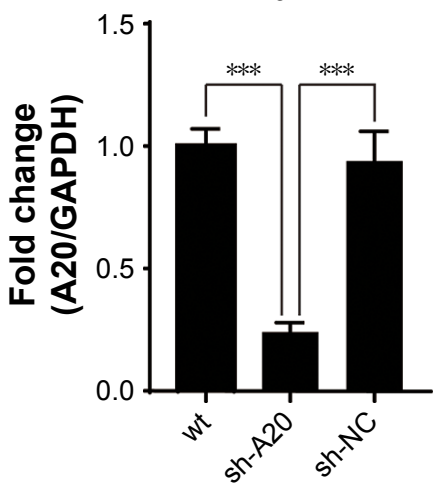

HepG2

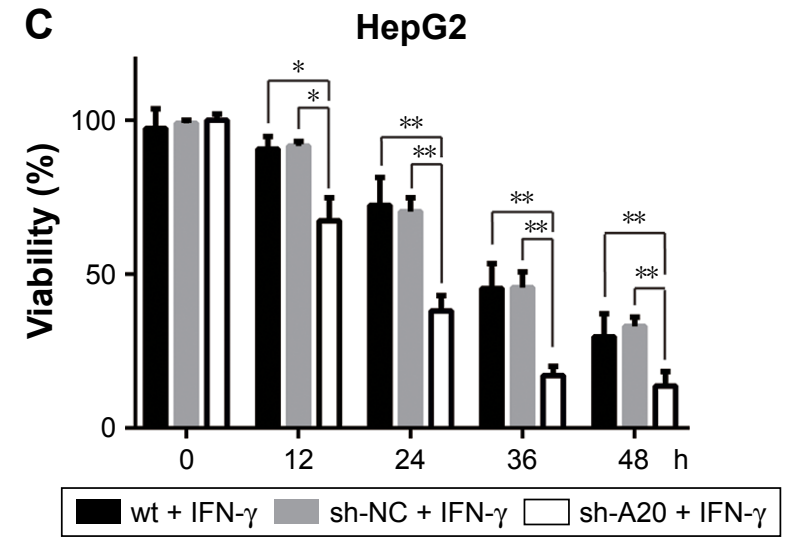

Huh7

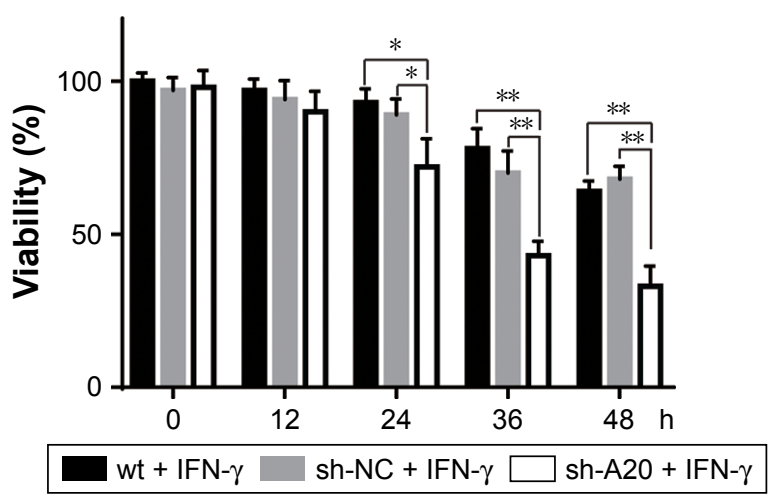

Figure I Knockdown of A20 enhances the antiproliferation ability of IFN- $\gamma$ in human hepatocellular carcinoma cells.

Notes: (A) The knockdown effect of A20 in HepG2 and Huh9 cells. Graphs represent quantification of target protein bands relative to GAPDH. (B) A20 knockdown cells (sh-A20), negative-control (sh-NC) and wild-type (wt) HepG2 and Huh9 cells were treated with various doses of IFN- $\gamma$ for 24 h, and cell viability was determined by the MTT assays. (C) A20 knockdown cells (sh-A20) and the control cells (sh-NC) HepG2 and Huh9 were treated with IFN- $\gamma(I 00 \mathrm{ng} / \mathrm{mL}$ ) for various time intervals, and cell viabilities were determined by the MTT assays. The data are represented as the mean \pm SD of three independent experiments. The significance was determined by the Student's $t$-test $(* P<0.05, * * P<0.01 ; * * * P<0.001)$.

Abbreviations: GAPDH, glyceraldehyde 3-phosphate dehydrogenase; IFN- $\gamma$, interferon gamma; MTT, 3-(4,5-dimethylthiazol-2-yl)-2,5-diphenyltetrazolium bromide; sh-A20, shRNA against human A20; sh-NC, shRNA against scrambled negative control; wt, wild type.

pathway plays an important role in the development of $\mathrm{HCC}$ and may be used as a therapeutic target. ${ }^{14,15}$ So we analyzed whether silencing of A20 combined with IFN- $\gamma$ affects the PI3K/Akt signaling pathway. We found that IFN- $\gamma$ treatment leads to a marked decrease of phosphorylated PI3K and Akt while the total PI3K and Akt remains constant in sh-A20 cells (Figure 4B).

\section{Downregulation of A20 enhanced} phosphorylation of STATI, which is required for IFN- $\gamma$-induced apoptosis in sh-A20 HepG2 cells

STAT1 and STAT3 are well-known downstream targets of IFN- $\gamma$ activation. Many studies indicated that STAT1 and/or 

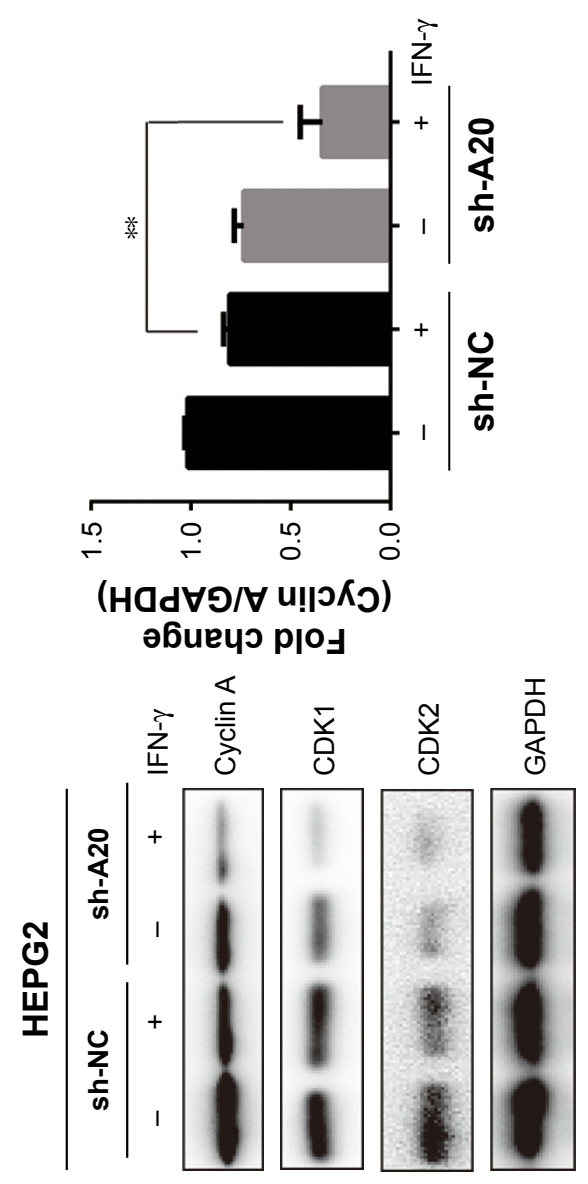

$\boldsymbol{m}$
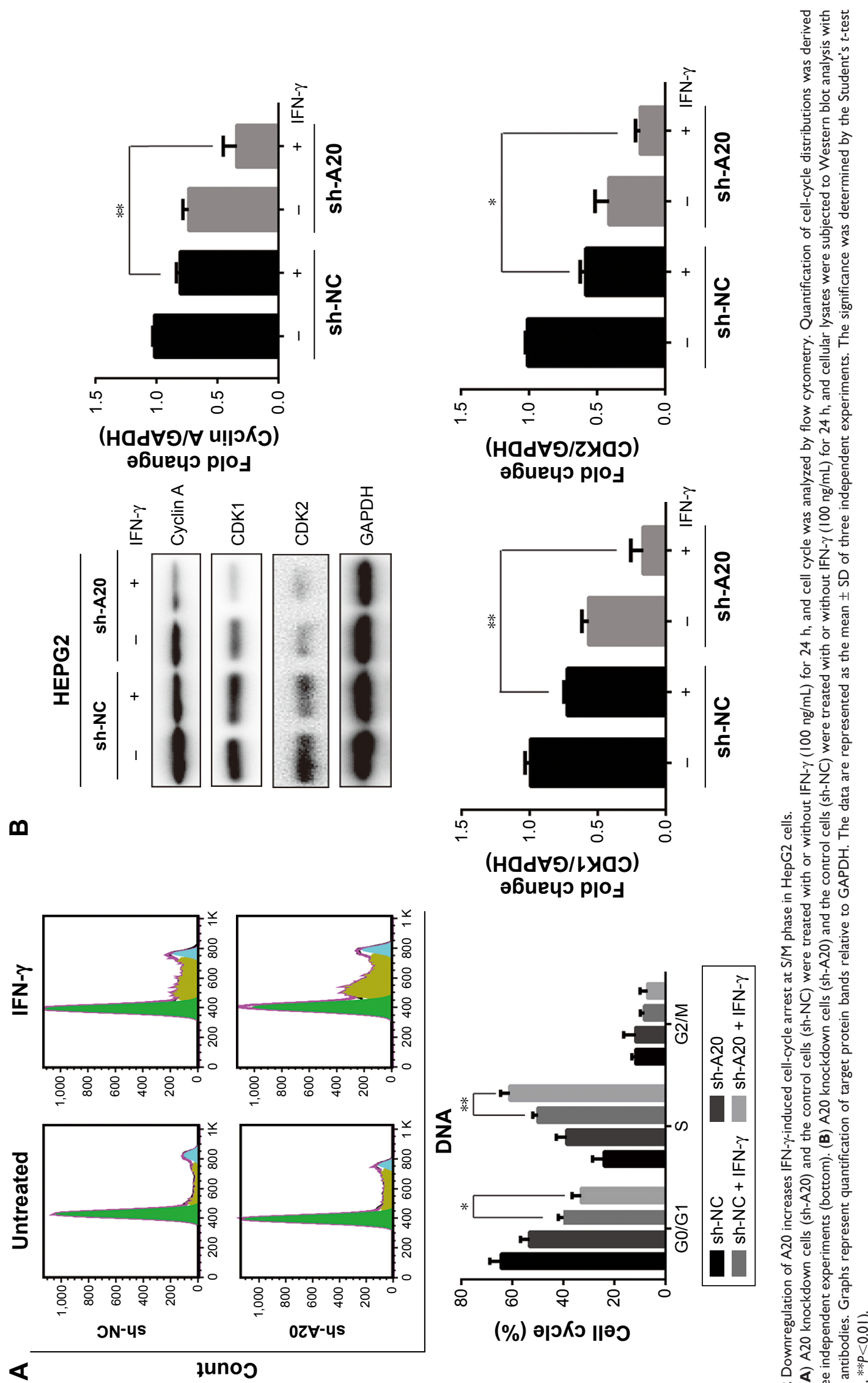

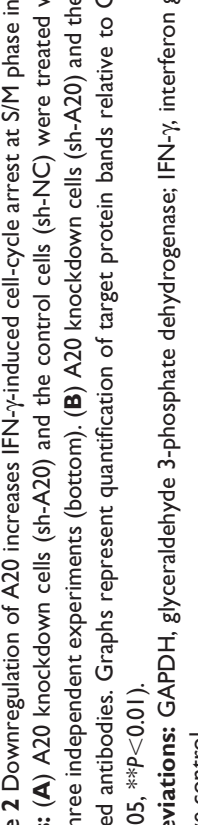

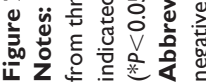


STAT3 play crucial roles in regulation of the activity of IFN- $\gamma .{ }^{16,17}$ To further delineate the mechanism underlying the cytotoxicity of IFN- $\gamma$ enhanced by downregulation of A20, we examined the change of STAT1 and STAT3 after treatment using the Western blot. As shown in Figure 5A, after the treatment with IFN- $\gamma$, both STAT3 and STAT1 were significantly upregulated in sh-A20 cells when compared with sh-NC cells. To investigate the role of STAT1 and STAT3, FLUD and S3I were employed to inhibit STAT1 and STAT3, respectively. Cell viability and apoptosis after the treatment with IFN- $\gamma$ in the presence of FLUD or S3I in sh-A20 cells were measured, and the results showed that S3I slightly repressed while FLUD fully repressed the cytotoxicity of IFN- $\gamma$ in sh-A20 cells. These data indicated that STAT1 but not STAT3 is critical for the cytotoxicity of IFN- $\gamma$ in sh-A20 cells.

\section{Discussion}

HCC is one of the most resistant carcinomas to conventional chemotherapy agents. Most HCC patients are diagnosed
A

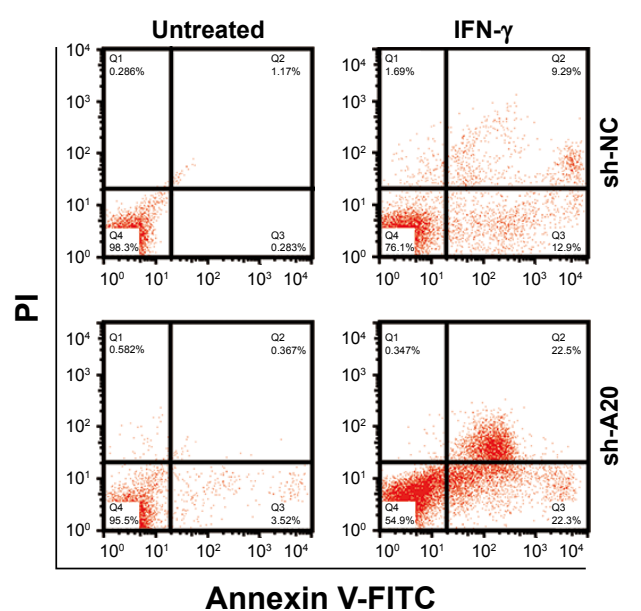

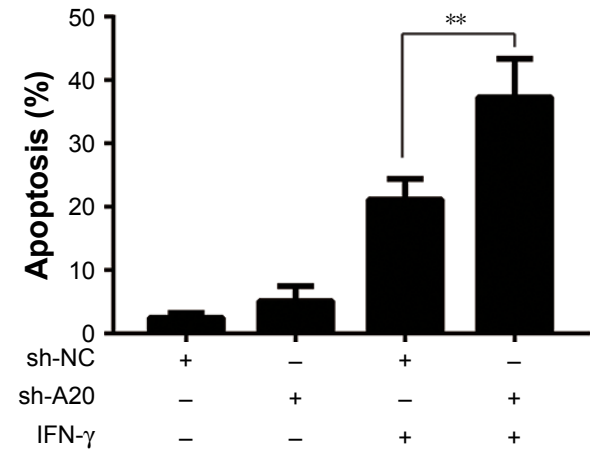

B

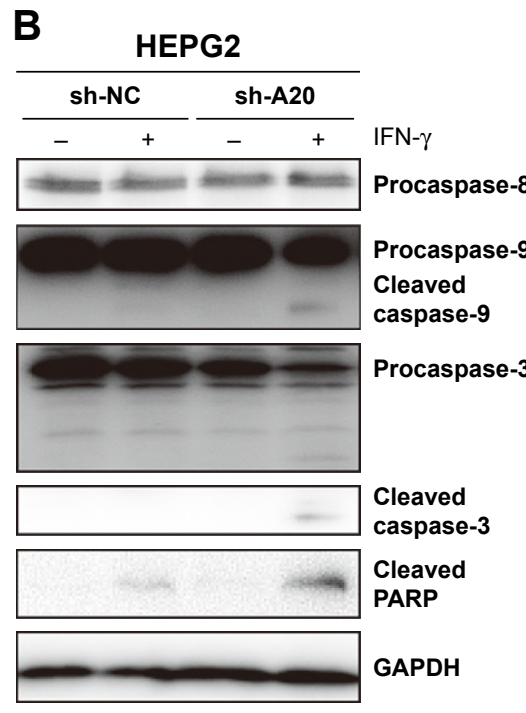

C

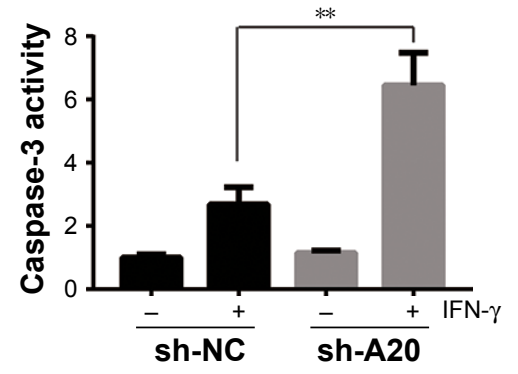

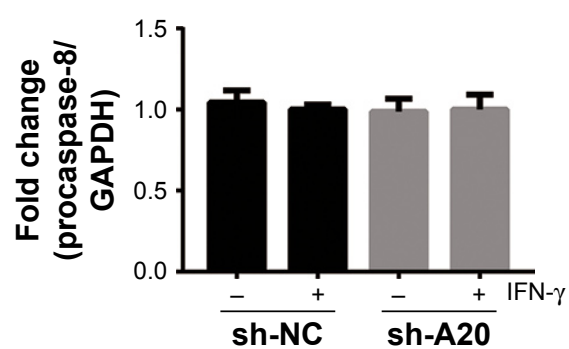
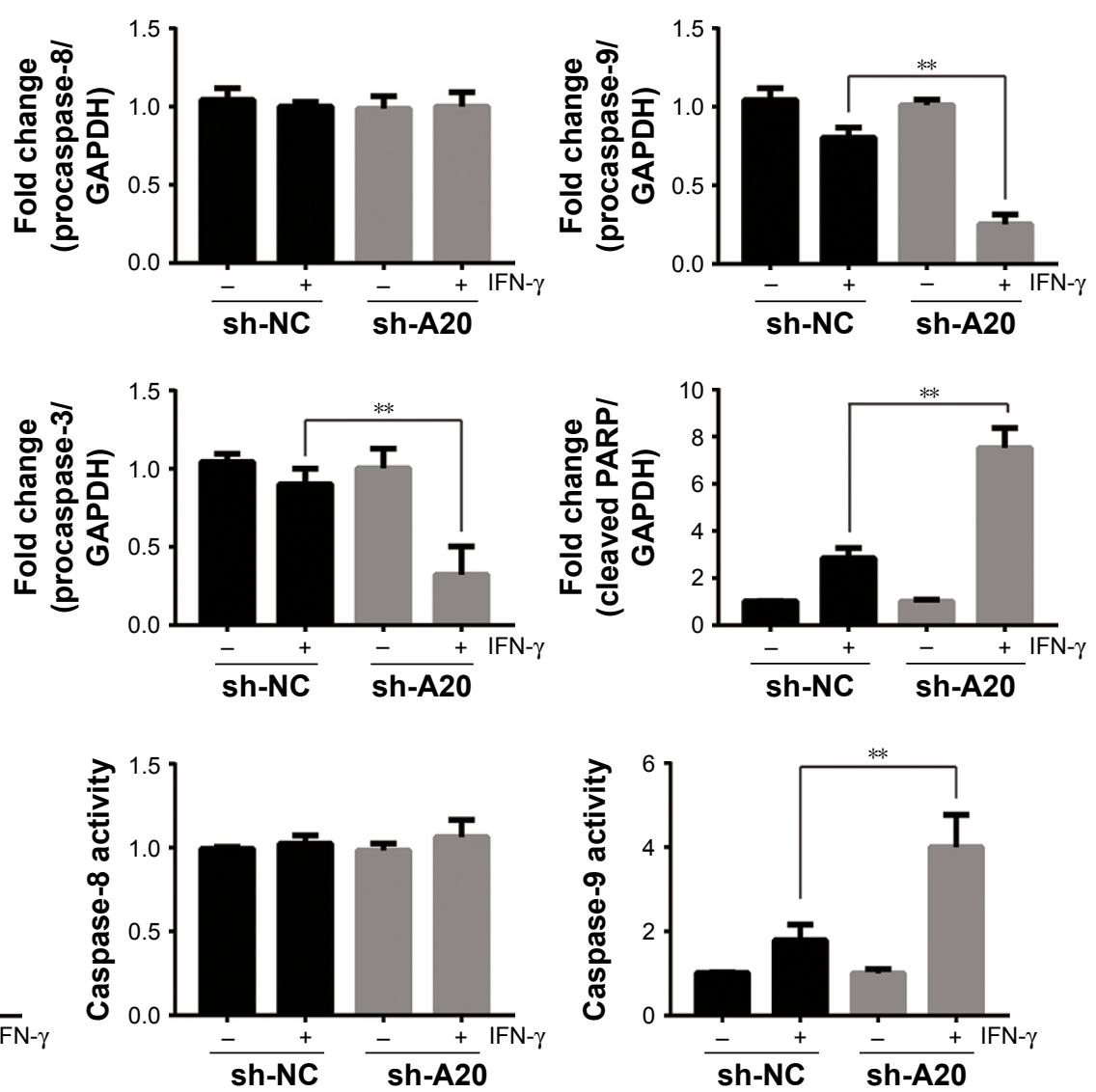

Figure 3 (Continued) 
D

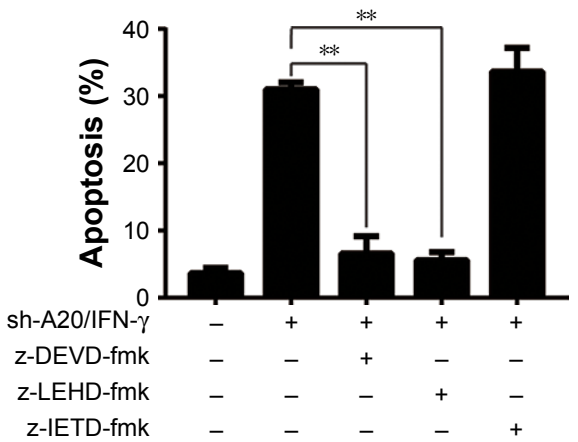

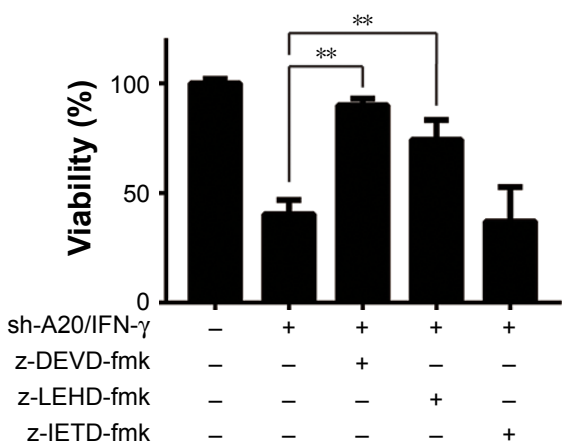

Figure 3 A20 knockdown increases the apoptosis induced by IFN- $\gamma$ in HepG2 cells.

Notes: (A) sh-NC and sh-A20 cells were treated with or without $100 \mathrm{ng} / \mathrm{mL}$ of IFN- $\gamma$ for $24 \mathrm{~h}$. Cells were then subjected to flow cytometry analysis using Annexin-V/ propidium iodide staining. Quantification of apoptosis was derived from three independent experiments (right). (B) sh-NC and sh-A20 cells were treated with or without $100 \mathrm{ng} / \mathrm{mL}$ of IFN- $\gamma$ for $24 \mathrm{~h}$. Cellular lysates were subjected to Western blot analysis with the indicated antibodies. Graphs represent quantification of target protein bands relative to GAPDH. (C) sh-NC and sh-A20 cells were treated with or without $100 \mathrm{ng} / \mathrm{mL}$ of IFN- $\gamma$ for 24 h. Cells were lysed and assayed for caspase-3, -8 and -9 activity. Graphs represent the mean \pm SD of three independent experiments. (D) sh-A20 cells were incubated with $100 \mathrm{ng} / \mathrm{mL}$ of IFN- $\gamma$ for $24 \mathrm{~h}$ after I h pretreatment with z-DEVDfmk, z-LEHD-fmk and z-IETD-fmk, respectively. Cell viability (left) was determined by MTT assay and apoptosis (right) was determined by flow cytometry. The data are represented as the mean \pm SD of three independent experiments. The significance was determined by the Student's $t$-test $(* * P<0.01)$.

Abbreviations: FITC, fluorescein isothiocyanate; GAPDH, glyceraldehyde 3-phosphate dehydrogenase; IFN- $\gamma$, interferon gamma; MTT, 3-(4,5-dimethylthiazol-2-yl)-2,5diphenyltetrazolium bromide; PI, propidium iodide; sh-A20, shRNA against human A20; sh-NC, shRNA against scrambled negative control.

at advanced or intermediate stages, rendering only small portion of patients eligible for surgery or liver transplantation. Therefore, searching for novel therapy for HCC is imperative. IFN- $\gamma$ is a cytokine that possesses various biological activities such as immunomodulatory, antiproliferative, antiviral and apoptosis-inducing effects. ${ }^{3,8}$ IFN- $\gamma$ not only shows antitumor activity against HCC but also inhibits replication of hepatitis $\mathrm{B}$ virus, which is a significant cause
A

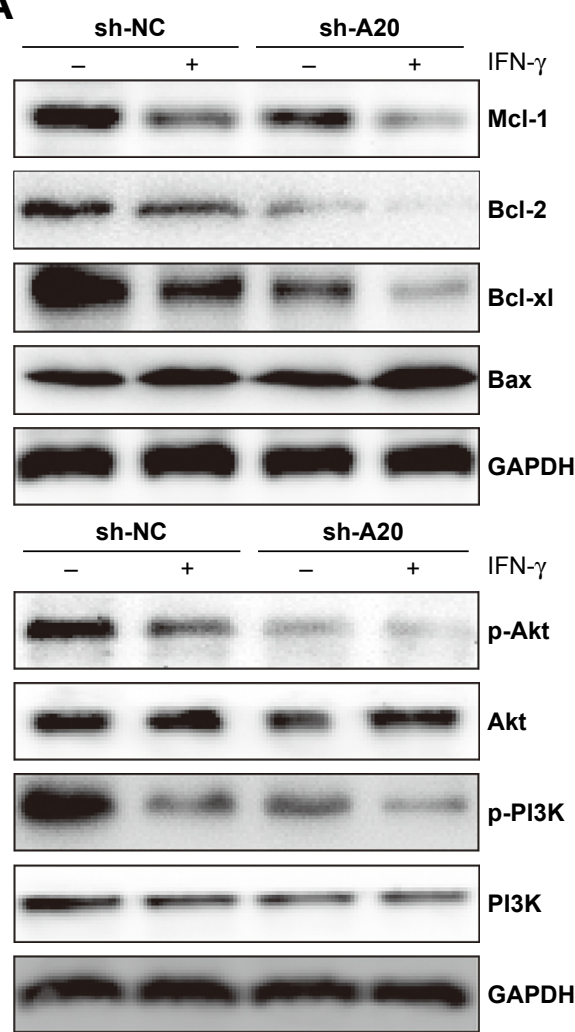

B
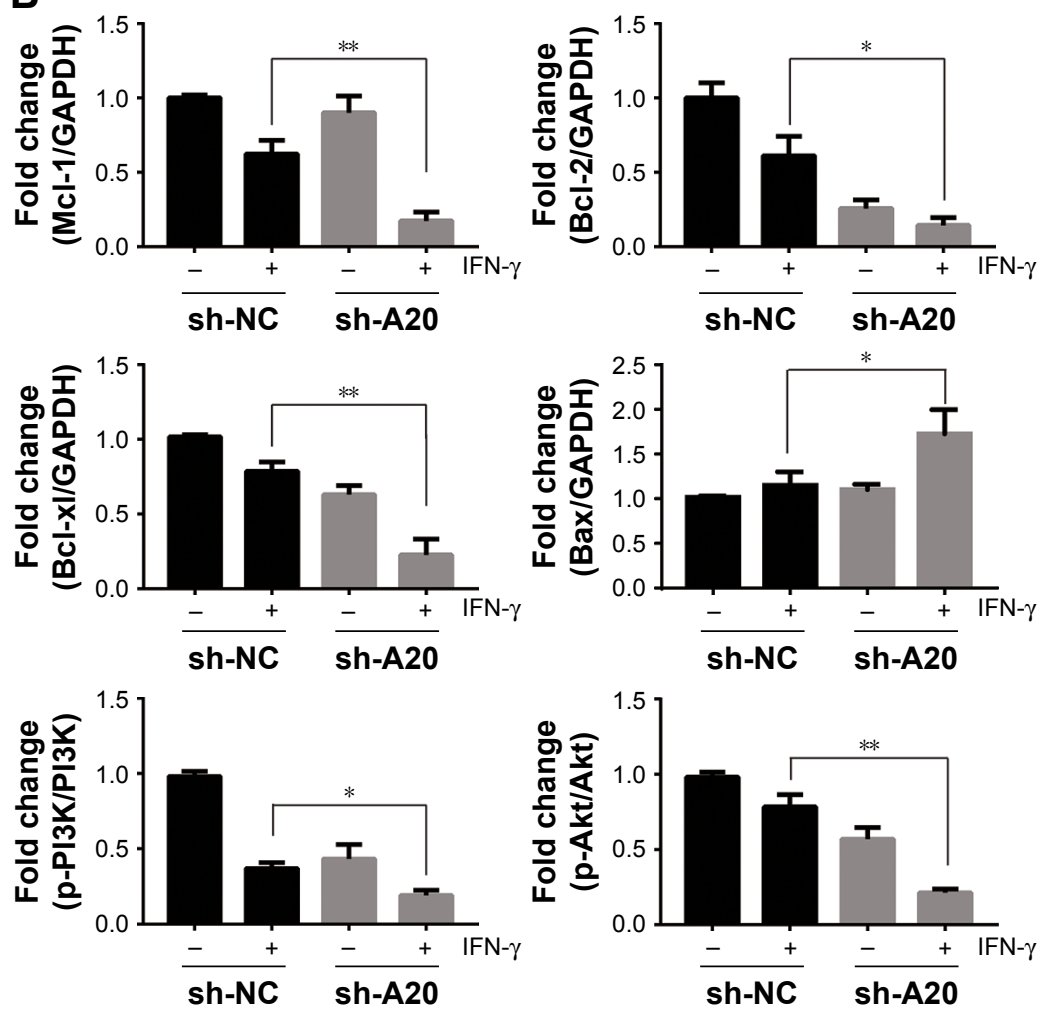

Figure 4 Silencing of A20 combined with IFN- $\gamma$ treatment leads to repression of antiapoptotic Bcl-2 proteins and PI3K/Akt signaling pathway.

Notes: (A) sh-NC and sh-A20 were treated with or without $100 \mathrm{ng} / \mathrm{mL}$ of IFN- $\gamma$ for $24 \mathrm{~h}$. Cellular lysates were subjected to Western blot analysis with the indicated antibodies. (B) Graphs represent quantification of target protein bands relative to GAPDH/total Akt/total PI3K. The data are represented as the mean \pm SD of three independent experiments. The significance was determined by the Student's $t$-test $(* P<0.05, * * P<0.01)$.

Abbreviations: FITC, fluorescein isothiocyanate; GAPDH, glyceraldehyde 3-phosphate dehydrogenase; IFN- $\gamma$, interferon gamma; MTT, 3-(4,5-dimethylthiazol-2-yl)-2,5diphenyltetrazolium bromide; PI3K, phosphoinositide 3-kinase; sh-A20, shRNA against human A20; sh-NC, shRNA against scrambled negative control. 
A

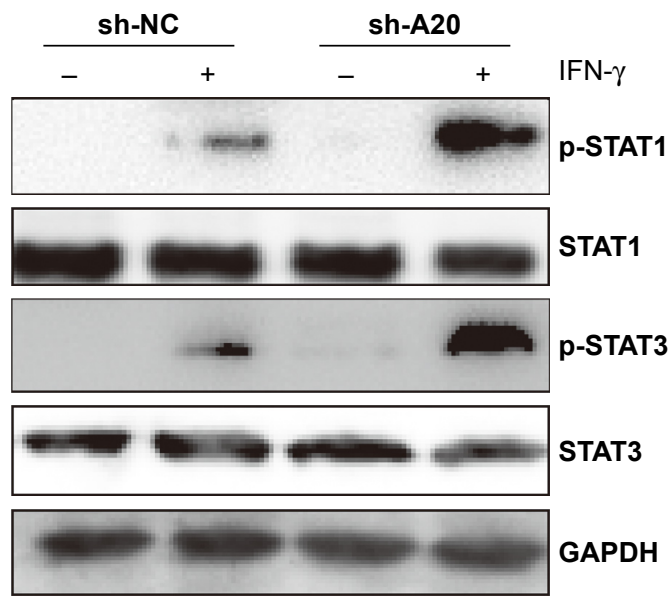

B

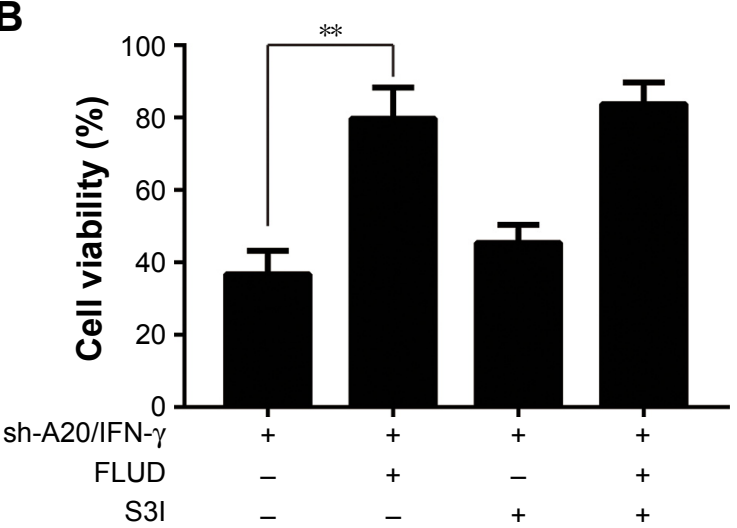

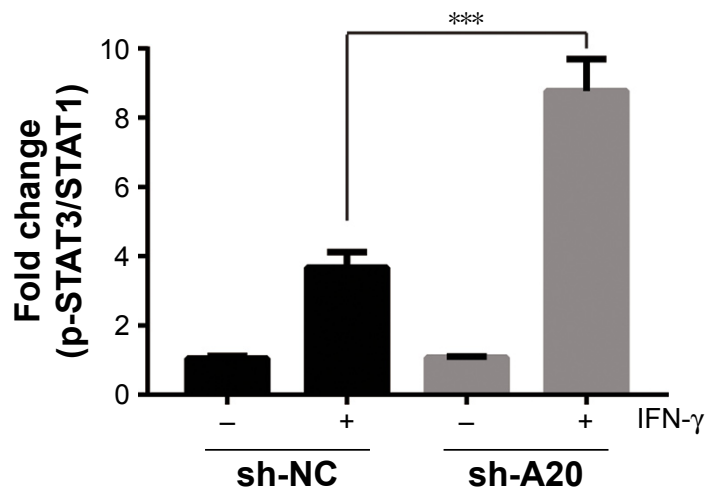
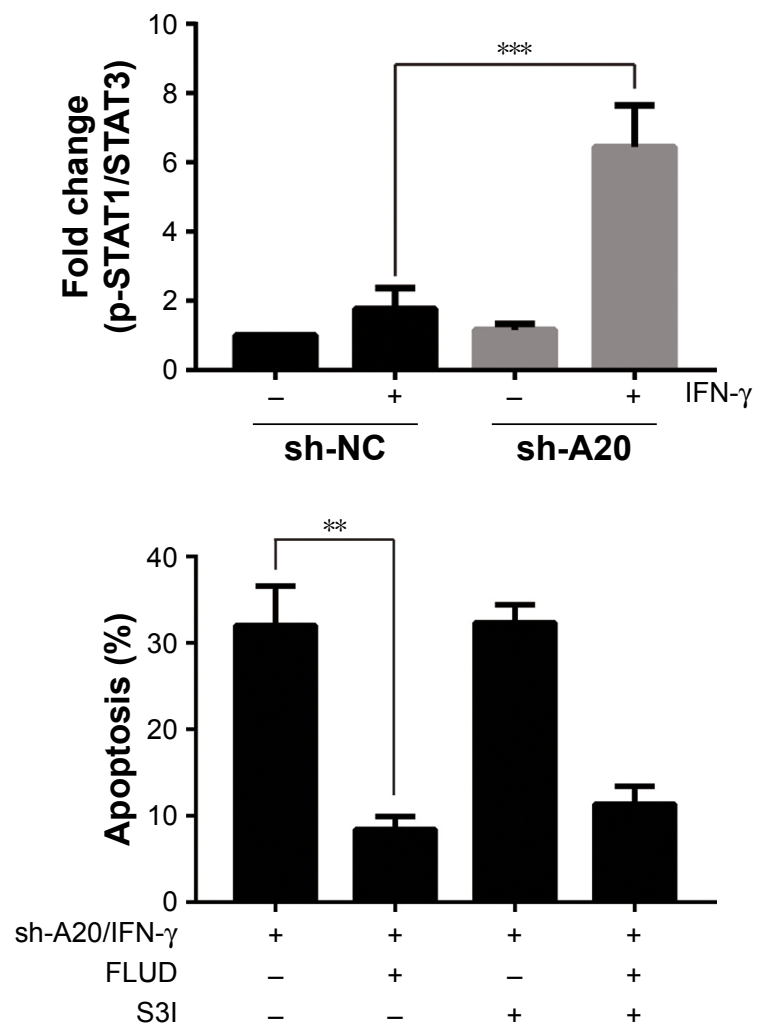

Figure 5 Downregulation of A20 enhances the antitumor effect of IFN- $\gamma$, which is dependent on the activation of STATI but not STAT3.

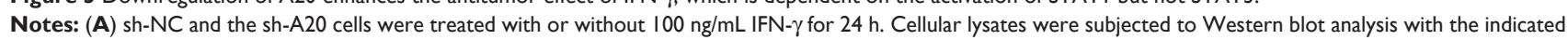
antibodies. Graphs represent quantification of target protein bands relative to STATI/STAT3. (B) sh-A20 cells were treated with IFN- $\gamma$ (I00 ng/mL) in the presence of P-STATI inhibitor or P-STAT3 inhibitor for $24 \mathrm{~h}$, and cell viability (left) and apoptosis (right) were measured using the MTT assay and Western blot, respectively. The data are represented as the mean $\pm S D$ of three independent experiments. The significance was determined by the Student's $t$-test $(* * P<0.0 \mathrm{I} ; * * * P<0.00 \mathrm{I})$.

Abbreviations: FLUD, fludarabine; GAPDH, glyceraldehyde 3-phosphate dehydrogenase; IFN- $\gamma$, interferon gamma; MTT, 3-(4,5-dimethylthiazol-2-yl)-2,5-diphenyltetrazolium bromide; PI3K, phosphoinositide 3-kinase; sh-A20, shRNA against human A20; sh-NC, shRNA against scrambled negative control.

of HCC. ${ }^{18,19}$ However, long-term administration of IFN- $\gamma$ is required to achieve therapeutic efficacy, which often induces side effects in patients. ${ }^{8}$ To overcome these limitations, great efforts have been made to improve the antitumor activity of IFN- $\gamma$. In the present study, we demonstrated that silencing of A20 can enhance the antitumor effect of IFN- $\gamma$ in HCC HepG2 and Huh9 cells.

A20 is considered as an oncogene because of its upregulation in various solid tumors. In contrast, A20 functions as a tumor suppressor in lymphoma because A20 deletion and mutation are prevalent in lymphoma. ${ }^{20}$ So the precise biological functions of A20 need further investigations in different tumor types. We first analyzed whether A20 could affect the antiproliferation activity of IFN- $\gamma$. MTT results showed that IFN- $\gamma$ was able to repress the viability of HepG2 cells and that downregulation of A20 further increased the antiproliferation ability of IFN- $\gamma$.

To investigate the mechanism of targeting A20 in combination with IFN- $\gamma$ decreasing the proliferation of HCC cells, we determined whether cell-cycle arrest was involved in this process. In our study, we found that treatment of IFN- $\gamma$ leads to more cell-cycle arrest at the $\mathrm{S}$ phase in sh-A20 cells compared 
with sh-NC cells. Noteworthy, downregulation of A20 or treatment with IFN- $\gamma$ alone could induce slight cell-cycle arrest as well. In previous studies, it was found that IFN- $\gamma$ could induce $S$ phase block in glioblastoma cells and G0/G1 phase block in gastric cancer cells. ${ }^{21,22}$ In addition, downregulation of A20 could induce cell-cycle arrest at G0/G1 phase in acute lymphoblastic leukemia cells. This discrepancy may be caused by different cell types and further investigation is required. Cell-cycle progress is regulated by cyclin, CDK and CDKIs. Further mechanistic studies demonstrated that silencing of A20 combined with IFN- $\gamma$ induces cell-cycle arrest through downregulation of cyclin A, CDK1 and CDK2.

A20 has been identified as an antiapoptotic protein in many tumors, and overexpression of A20 is able to block apoptosis. ${ }^{23,24}$ IFN- $\gamma$ has been found to be able to induce apoptosis in HCC cells. ${ }^{25}$ We hypothesized that A20 may negatively regulate IFN- $\gamma$-induced apoptosis. As expected, IFN- $\gamma$ induced more apoptosis in sh-A20 cells than in sh-NC cells. Since whether IFN- $\gamma$-induced apoptosis is caspasedependent remains controversial. ${ }^{26}$ We next examined the activation of caspases and found that silencing of A20 combined with IFN- $\gamma$ further promoted the activation of caspase-3, -9 but not caspase-8. It was also observed that caspase- 3 and -9 inhibitor but not caspase- 8 inhibitor could repress the cytotoxic effect of IFN- $\gamma$ in sh-A20 cells. Our findings were similar with a previous report in which IFN- $\gamma$ synergistically acts with LIGHT to induce apoptosis in HCC cells via activation of caspase-3/-9 but not caspase- $8 .{ }^{27} \mathrm{Bcl}-2$ proteins are well-known regulators of apoptosis and are able to protect cells from apoptosis induced by various stimuli. ${ }^{28}$ It has been reported that the expression of $\mathrm{Bcl}-2$ proteins can be downregulated by IFN- $\gamma$ or downregulation of A20. ${ }^{12,29}$ So we also examined whether the expressions of Bcl-2 proteins are affected by treatment with IFN- $\gamma$ and silencing of A20. We found that Bcl-2, Mc-1 and Bcl-xl were significantly repressed while Bax was upregulated by the treatment with IFN- $\gamma$ in sh-A20 cells. As Bcl-2 proteins are known to function upstream of caspases, this finding may explain why caspase-9 and caspase-3 were significantly activated.

$\mathrm{PI} 3 \mathrm{~K} / \mathrm{Akt}$ signaling has been found to be involved in not only the development of HCC but also various other carcinomas such as bladder cancer, renal cancer and colorectal cancer. ${ }^{30-32}$ Therefore, we checked the change of PI3K/Akt signaling pathway. In our study, we found that silencing of A20 or treatment with IFN- $\gamma$ is able to inhibit the activation of PI3K/Akt and this effect can be augmented by the combination of both. As targeting the PI3K/Akt can overcome IFN- $\gamma$ resistance in gastric cancer as well, ${ }^{33}$ for future studies, ablating IFN- $\gamma$ resistance by targeting PI3K/Akt may show benefits for treating HCC and other IFN- $\gamma$-resistant and PI3K/ Akt-related human diseases. It has also been known that signaling of IFN- $\gamma$ is mediated by JAK-STAT pathway. ${ }^{30}$ The activation of JAK-STAT signaling pathway plays an important role in IFN- $\gamma$-induced apoptosis in carcinoma cells. ${ }^{34}$ After binding to its receptor, IFN- $\gamma$ activates JAKs that lead to the phosphorylation of STAT1, which functions as a transcription factor. Besides STAT1, IFN- $\gamma$ could also activate STAT3 and STAT5. ${ }^{35}$ A20 has been found to affect the IFN- $\gamma$ signaling via regulating expression levels of STATs. ${ }^{36}$ In our study, we found that downregulation of A20 could enhance the activation of STAT1 and STAT3 induced by IFN- $\gamma$. These findings were quite similar to a previous study. ${ }^{36}$ To further explore the role of STAT1 and STAT3 in IFN- $\gamma$-induced apoptosis, we used STAT1 and STAT3 inhibitor (FLUD and S3I, respectively) and observed that FLUD but not S3I could inhibit the cytotoxicity of IFN- $\gamma$. Earlier study has found that STAT1 activation is critical for IFN- $\gamma$-induced antiproliferative, proapoptotic effects. ${ }^{37}$ Our data further confirmed the vital role of STAT1 in the antitumor effects of IFN- $\gamma$.

\section{Conclusion}

In summary, we demonstrate for the first time that silencing of A20 could serve as a collaborative treatment to IFN- $\gamma$ in HCC cells, resulting in inhibition of cell viability, and increase of cell arrest and apoptosis. In addition, silencing of A20 combined with IFN- $\gamma$ leads to repression of antiapoptotic Bcl-2 proteins, inhibition of PI3K/Akt signaling pathway and activation of STAT1. Consequently, A20 downregulation in line with IFN- $\gamma$ could potentially serve as an important strategy against HCC.

\section{Acknowledgments}

This study was funded by the National Natural Science Foundation for Young Scientists of China (No 81602466) and Foundation of Shanghai Health and Family Planning Commission (No 201640164).

\section{Disclosure}

The authors report no conflicts of interest in this work.

\section{References}

1. El-Serag HB, Rudolph KL. Hepatocellular carcinoma: epidemiology and molecular carcinogenesis. Gastroenterology. 2007;132(7): 2557-2576.

2. Farazi PA, Glickman J, Horner J, Depinho RA. Cooperative interactions of p53 mutation, telomere dysfunction, and chronic liver damage in hepatocellular carcinoma progression. Cancer Res. 2006; 66(9):4766-4773.

3. Pestka S, Krause CD, Walter MR. Interferons, interferon-like cytokines, and their receptors. Immunol Rev. 2004;202:8-32. 
4. Janardhanan R, Banik NL, Ray SK. N-(4-Hydroxyphenyl)retinamide induced differentiation with repression of telomerase and cell cycle to increase interferon-gamma sensitivity for apoptosis in human glioblastoma cells. Cancer Lett. 2008;261(1):26-36.

5. Lee SH, Kim JW, Oh SH, et al. IFN-gamma/IRF-1-induced p27kip1 down-regulates telomerase activity and human telomerase reverse transcriptase expression in human cervical cancer. FEBS Lett. 2005; 579(5):1027-1033.

6. Kuga H, Morisaki T, Nakamura K, et al. Interferon-gamma suppresses transforming growth factor-beta-induced invasion of gastric carcinoma cells through cross-talk of Smad pathway in a three-dimensional culture model. Oncogene. 2003;22(49):7838-7847.

7. Lindkvist A, Ivarsson K, Jernberg-Wiklund H, Paulsson-Karlsson Y. Interferon-induced sensitization to apoptosis is associated with repressed transcriptional activity of the hTERT promoter in multiple myeloma. Biochem Biophys Res Commun. 2006;341(4):1141-1148.

8. Miller CH, Maher SG, Young HA. Clinical use of interferon-gamma. Ann N Y Acad Sci. 2009;1182:69-79.

9. Mizokami MM, Hu P, Khawli LA, Li J, Epstein AL. Chimeric TNT-3 antibody/murine interferon-gamma fusion protein for the immunotherapy of solid malignancies. Hybrid Hybridomics. 2003;22(4):197-207.

10. Dixit VM, Green S, Sarma V, et al. Tumor necrosis factor-alpha induction of novel gene products in human endothelial cells including a macrophage-specific chemotaxin. J Biol Chem. 1990;265(5): 2973-2978

11. Hymowitz SG, Wertz IE. A20: from ubiquitin editing to tumour suppression. Nat Rev Cancer. 2010;10(5):332-341.

12. Chen H, Hu L, Luo Z, et al. A20 suppresses hepatocellular carcinoma proliferation and metastasis through inhibition of Twist 1 expression. Mol Cancer. 2015;14:186.

13. Dong B, Lv G, Wang Q, et al. Targeting A20 enhances TRAIL-induced apoptosis in hepatocellular carcinoma cells. Biochem Biophys Res Commun. 2012;418(2):433-438.

14. Singh AR, Joshi S, Burgoyne AM, et al. Single agent and synergistic activity of the "first-in-class" dual PI3K/BRD4 inhibitor SF1126 with sorafenib in hepatocellular carcinoma. Mol Cancer Ther. 2016; 15(11):2553-2562.

15. Millis SZ, Ikeda S, Reddy S, Gatalica Z, Kurzrock R. Landscape of phosphatidylinositol-3-kinase pathway alterations across 19,784 diverse solid tumors. JAMA Oncol. 2016;2(12):1565-1573.

16. Bai Y, Ahmad U, Wang Y, et al. Interferon-gamma induces X-linked inhibitor of apoptosis-associated factor-1 and Noxa expression and potentiates human vascular smooth muscle cell apoptosis by STAT3 activation. J Biol Chem. 2008;283(11):6832-6842.

17. Fang P, Hwa V, Little BM, Rosenfeld RG. IGFBP-3 sensitizes prostate cancer cells to interferon-gamma-induced apoptosis. Growth Horm IGF Res. 2008;18(1):38-46.

18. Kan QC, Li DL, Yu ZJ. Vector-mediated expression of interferon gamma inhibits replication of hepatitis B virus in vitro. Acta Virologica. 2013;57(4):421-428.

19. Li P, Du Q, Cao Z, et al. Interferon-gamma induces autophagy with growth inhibition and cell death in human hepatocellular carcinoma (HCC) cells through interferon-regulatory factor-1 (IRF-1). Cancer Lett. 2012;314(2):213-222.
20. Kato M, Sanada M, Kato I, et al. Frequent inactivation of A20 in B-cell lymphomas. Nature. 2009;459(7247):712-716.

21. Liu Y, Chen N, Yin H, et al. A placental growth factor-positively charged peptide potentiates the antitumor activity of interferon-gamma in human brain glioblastoma U87 cells. Am J Cancer Res. 2016;6(2): 214-225.

22. Zhao YH, Wang T, Yu GF, et al. Anti-proliferation effects of interferongamma on gastric cancer cells. Asian Pac J Cancer Prev. 2013;14(9): 5513-5518.

23. Opipari AW Jr, Hu HM, Yabkowitz R, Dixit VM. The A20 zinc finger protein protects cells from tumor necrosis factor cytotoxicity. $J$ Biol Chem. 1992;267(18):12424-12427.

24. Fries KL, Miller WE, Raab-Traub N. Epstein-Barr virus latent membrane protein 1 blocks p53-mediated apoptosis through the induction of the A20 gene. $J$ Virol. 1996;70(12):8653-8659.

25. Komita H, Homma S, Saotome H, Zeniya M, Ohno T, Toda G. Interferon-gamma produced by interleukin-12-activated tumor infiltrating CD8+T cells directly induces apoptosis of mouse hepatocellular carcinoma. J Hepatol. 2006;45(5):662-672.

26. Sasagawa T, Hlaing M, Akaike T. Synergistic induction of apoptosis in murine hepatoma Hepa1-6 cells by IFN-gamma and TNF-alpha. Biochem Biophys Res Commun. 2000;272(3):674-680.

27. Li J, Shen F, Wu D, et al. Expression level of Bcl-XL critically affects sensitivity of hepatocellular carcinoma cells to LIGHT-enhanced and interferon-gamma-induced apoptosis. Oncol Rep. 2007;17(5): $1067-1075$

28. Adams JM, Cory S. The Bcl-2 protein family: arbiters of cell survival. Science. 1998;281(5381):1322-1326.

29. Mukherjee S, Biswas T. Activation of TOLLIP by porin prevents TLR2associated IFN-gamma and TNF-alpha-induced apoptosis of intestinal epithelial cells. Cell Signal. 2014;26(12):2674-2682.

30. Lamarca A, Mendiola M, Barriuso J. Hepatocellular carcinoma: exploring the impact of ethnicity on molecular biology. Crit Rev Oncol Hematol. 2016;105:65-72.

31. Yu R, Yu BX, Chen JF, et al. Anti-tumor effects of Atractylenolide I on bladder cancer cells. J Exp Clin Cancer Res. 2016;35:40.

32. Brown JS, Banerji U. Maximising the potential of AKT inhibitors as anti-cancer treatments. Pharmacol Ther. 2017;172:101-115.

33. Tseng PC, Huang WC, Chen CL, et al. Regulation of SHP2 by PTEN/ AKT/GSK-3beta signaling facilitates IFN-gamma resistance in hyperproliferating gastric cancer. Immunobiology. 2012;217(9):926-934.

34. Chin YE, Kitagawa M, Kuida K, Flavell RA, Fu XY. Activation of the STAT signaling pathway can cause expression of caspase 1 and apoptosis. Mol Cell Biol. 1997;17(9):5328-5337.

35. Ramana CV, Gil MP, Schreiber RD, Stark GR. Stat1-dependent and -independent pathways in IFN-gamma-dependent signaling. Trends Immunol. 2002;23(2):96-101.

36. Moll HP, Lee A, Minussi DC, et al. A20 regulates atherogenic interferon (IFN)-gamma signaling in vascular cells by modulating basal IFNbeta levels. J Biol Chem. 2014;289(45):30912-30924.

37. Bromberg JF, Horvath CM, Wen Z, Schreiber RD, Darnell JE Jr. Transcriptionally active Stat1 is required for the antiproliferative effects of both interferon alpha and interferon gamma. Proc Natl Acad Sci US Am. 1996;93(15):7673-7678.
Drug Design, Development and Therapy

\section{Publish your work in this journal}

Drug Design, Development and Therapy is an international, peerreviewed open-access journal that spans the spectrum of drug design and development through to clinical applications. Clinical outcomes, patient safety, and programs for the development and effective, safe, and sustained use of medicines are the features of the journal, which

\section{Dovepress}

has also been accepted for indexing on PubMed Central. The manuscript management system is completely online and includes a very quick and fair peer-review system, which is all easy to use. Visit http://www.dovepress.com/testimonials.php to read real quotes from published authors. 